\title{
Assessment of polyphenol oxidase and peroxidase activity in root of Basella Alba induced by high temperature stress
}

\author{
Md. Shahidul Haque ${ }^{1 *}$, Md. Monirul Islam ${ }^{1}$, Md. Amirul Islam ${ }^{1}$, M.M.H. Khan ${ }^{1}$ \\ and Md. Ziaul Amin ${ }^{2}$ \\ ${ }^{I}$ Department of Biochemistry and Molecular Biology, Laboratory of Protein and Enzyme Research, University \\ of Rajshahi, Rajshahi-6205, Bangladesh \\ ${ }^{2}$ Department of Genetic Engineering and Biotechnology, Jessore University of Science and Technology, Jessore, \\ Bangladesh
}

\begin{abstract}
Polyphenol oxidase and peroxidase are recognized to be antioxidative enzymes playing the critical role in metabolic regulation in plants. However, the regulatory mechanism of these enzymes in root of Basella alba in response to high temperature stress is not clarified. Plants grown in different pots were exposed to 45 ${ }^{\circ} \mathrm{C}$ for $24 \mathrm{~h}$, $48 \mathrm{~h}$ and $72 \mathrm{~h}$ periods and the respective controls were kept in $30^{\circ} \mathrm{C}$. Dose response specificity of substrate was performed during the assay of polyphenol oxidase (PPO). In roots of different treatments, the PPO activity have been found to increase with 10, 100 and $200 \mathrm{mM}$ substrate concentration for $24 \mathrm{~h}$, 48h and $72 \mathrm{~h}$, however the effects were found to be more pronounced at $10 \mathrm{mM}$ for $24 \mathrm{~h}$ periods although different substrate concentrations increased activity dose dependently showing the validity of substrate effects. Conversely, the reciprocal findings were noted for POD whenever plants were exposed to high temperature for the above mentioned periods and the activities in root were down regulated, reduced maximally for $48 \mathrm{~h}$ periods respectively when compared to respective controls. The results agree that these enzymes are differentially regulated in root and may play the critical role in survival of the species in adverse environment.
\end{abstract}

Keywords: Temperature stress, metabolic effects, Basella alba, adaptive response

\section{Introduction}

Plants frequently encounter unfavorable growth conditions in the biosphere. Climatic factors, such as extreme temperatures (heat, cold, freezing), drought and contamination of soils by high salt concentration, are major abiotic environmental stresses that limit plant growth and development and thus agronomical yield and play a major role in determining the geographic distribution of plant species. Different plant species are highly variable with respect to their optimum environments, and a harsh environmental condition, which is harmful for one plant species, might not be stressful for another (1). This is also reflected in the multitude of different stress-response mechanisms. Diverse environmental stresses differentially affect plant processes that lead to loss of cellular homeostasis accompanied by the formation of reactive oxygen species (ROS), which causes oxidative damage to membrane, lipids, proteins and nucleic acids (2). To prevent the oxidative damage caused by such abiotic stress, plants generate the different mechanism by which they survive in such critical environment. Anti oxidative enzymes like superoxide dismutase, catalase and peroxidase are the most important components in the scavenging system of ROS. Several lines of evidences reveal that anti oxidative enzymes and anti oxidant molecules can neutralize ROS $(3,4)$. It has been revealed that heat stress adversely affect grain yield in wheat (5). Therefore, it is well recognized that high temperature is critically involved in diverse metabolic regulation and the oxidative stress caused by high temperature therefore, is involved in inducing the synthesis of ROS which damages and injury to the plants. However, plants adapt to this adverse situation by synthesis of some enzymes which play the critical role in metabolic regulation and coordination in the biosphere.

Enzymes that destroy phenolics are well studied and ubiquitous in plants. The enzymatic destruction of phenolics is typically an oxidative process with molecular oxygen $\left(\mathrm{O}_{2}\right)$ serving as the oxidant for oxidases and hydrogen peroxide $\left(\mathrm{H}_{2} \mathrm{O}_{2}\right)$ as the oxidant for peroxidases (6). Phenolic oxidases and peroxidases are ubiquitous in vascular plants, mosses and fungi. In plants, the enzymes are typically concentrated in shoot tissues that contain plastids (chiefly chloroplasts) fruits and seeds (6) but have also been found in either aerial roots of orchids (7) or belowground tubers (8). Polyphenol oxidase (PPO) and peroxidase (POD) have been widely recognized to be an anti oxidative causing the biosynthesis of diverse metabolites essential for diagnosis and other purposes (9) and have been found to be involved in scavenging system of reactive oxygen species synthesized in the biological system. Polyphenol oxidases are enzymes with molecular weight of $60 \mathrm{kDa}$ located in the chloroplast bound to thylakoid membranes, belonging to a group of copper containing metalloproteins and are members of oxido-reductases that catalyze the oxidation of a wide range of phenolic compounds by utilizing molecular oxygen (10). In presence of atmospheric oxygen and PPO, monophenol is 
hydroylated to o-diphenol and diphenol can be oxidized to o-quinones which then undergo polymerization to yield dark brown polymers. Peroxidases are a single-polypeptide chain, haemcontaining enzymes with molecular weight between 28 to $60 \mathrm{kDa}$ (11) and have been involved to oxidize a wide variety of organic and inorganic substrates by reducing $\mathrm{H}_{2} \mathrm{O}_{2}$ and peroxides. They are mainly located in the cell wall (12) and are one of the key enzymes controlling plant growth and development. During adverse environment induced by high temperature, these two enzymes might be involved in the prevention of oxidative damage in plant and therefore could be an essential index for the adaptive mechanism in adverse circumstances.

Basella alba is a very soft leafy vegetable available in Bangladesh and grows both in summer and winter. The diverse clinical importance of this plant was demonstrated by recent investigations $(13,14)$. Therefore, it is assumed that variation of temperature may affect both metabolic activities as well as its biological importance. The current investigation has been undertaken to find the role of high temperature treatment in the regulation of metabolic functions, particularly the regulation of antioxidative enzymes PPO and POD in emerging roots of the species B alba and may assist in the clarification of such stress induced mechanisms.

\section{Materials and Methods}

\subsection{Plant Materials and High Temperature Treatment}

For this experiment, two plastic pots were used; each pot size was $70 \mathrm{~cm}$ in diameter and $24 \mathrm{~cm}$ in height. An adequate amount of soil was taken in each plastic pot and the plastic pots were seeded with Basella alba. For the germination of seeds, the following points were carried out: i) the strong seeds were selected; the seeds were added to normal water and the floating seeds were discarded; ii) the seeds were kept in normal water with temperature below $37{ }^{\circ} \mathrm{C}$ for overnight; iii) the seeds which were swollen by water absorption, were expected to be effective for germination; iv) the seeds were seeded in the pots prepared with soil and the efficiency of seed germination was $65 \%-75 \%$. After 20 days of germination, the two different pots were described as control and high temperature induced plant. Control pot was used for $24 \mathrm{~h}, 48 \mathrm{~h}$ and $72 \mathrm{~h}$ treatments in room temperature, however, the temperature was maintained $30^{\circ} \mathrm{C}$ by using air cooling system (AC) already fixed in the room and without giving any high temperature. The second pot was used similarly for $24 \mathrm{~h}, 48 \mathrm{~h}$ and $72 \mathrm{~h}$ duration in the plastic chamber and was exposed to $45^{\circ} \mathrm{C}$ with full aeration along with sufficient water. To maintain this temperature, electric bulbs $(2 \times 200 \mathrm{~W})$ were connected to the chamber. After the treatments, the roots were collected consecutively from each pot for $24 \mathrm{~h}, 48 \mathrm{~h}$ and $72 \mathrm{~h}$ duration, washed with water and kept in $-80{ }^{\circ} \mathrm{C}$.

\subsection{Assay of Polyphenol Oxidase (PPO) Activity}

The roots of the different treatments $(24 \mathrm{~h}, 48 \mathrm{~h}$ and $72 \mathrm{~h})$ and their respective controls were homogenized with $15 \mathrm{~mL}$ of distilled water in a mortar kept on ice. Approximately, $0.25 \mathrm{~g}$ of high temperature induced and their respective control roots were used for homogenization. The homogenates were centrifuged at $9000 \mathrm{rpm}$ for $15 \mathrm{~min}$ and the supernatants were used as crude extract for assay of PPO activity spectrophotometrically as described by Mahadevan and Sridhar (15) based on an initial rate of increase in absorbance at $495 \mathrm{~nm}$ where, catechol was used as substrate. One unit of enzyme activity is defined as a change in absorbance of $0.001 \mathrm{~min}^{-1} \mathrm{~mL}^{-1}$ of enzyme extract. For determination of PPO activity in root, $4 \mathrm{~mL}$ of $0.1 \mathrm{M}$ phosphate buffer ( $\mathrm{pH}$ 6.0) and $1 \mathrm{~mL}$ of crude enzyme extract were taken in the test tube and kept on ice. The contents were mixed, placed in a spectrophotometer using a cuvette and the absorbance was adjusted to zero at $495 \mathrm{~nm}$. The cuvette was removed, $1 \mathrm{~mL}$ of catechol $(10 \mathrm{mM}, 100 \mathrm{mM}$ and $200 \mathrm{mM})$ was added, quickly mixed by inversion and the changes in absorbance at $495 \mathrm{~nm}$ were recorded for up to $3 \mathrm{~min}(1,2,3 \mathrm{~min})$. In all experiments, three replicates were performed for each sample. The following calculation was used to assay PPO activity in a sample: change in $A_{495}=A_{f}-A_{i}$, where, $A_{i}=$ initial absorbance reading and $A_{f}=$ final absorbance reading. Change in $\mathrm{A}_{495}$ for each sample was used to calculate the units of PPO activity and the activity is expressed as Unit $\mathrm{g}^{-1}$ of root weight.

\subsection{Assay of Peroxidase (POD) Activity}

The roots of the different treatments $(24 \mathrm{~h}, 48 \mathrm{~h}$ and $72 \mathrm{~h})$ and their respective controls were homogenized with $12 \mathrm{~mL}$ of $0.5 \mathrm{M}$ phosphate buffer ( $\mathrm{pH} 7.0$ ) in a mortar kept on ice. Approximately, $0.25 \mathrm{~g}$ of high temperature induced and their respective control roots were used for homogenization. The homogenates were centrifuged at $9000 \mathrm{rpm}$ for $15 \mathrm{~min}$ and the supernatants were used as crude extract for assay of POD activity as described by Daz et al. (16). Peroxidase activity was determined spectrophotometrically at $470 \mathrm{~nm}$ using guaiacol as a phenolic substrate with hydrogen peroxide. The enzymatic oxidation of guaiacol changed the substrate into orange-pink product which was measured by spectrophotometer as a change in absorbance of $0.001 \mathrm{~min}^{-1}$ and the absorbance was recorded for up to $4 \mathrm{~min}$. For determination of POD activity in root, 2.5 $\mathrm{mL}$ of $0.1 \mathrm{M}$ phosphate buffer (pH 7.0), $1 \mathrm{~mL}$ of crude enzyme extract and $0.6 \mathrm{~mL}$ of $1 \%(\mathrm{v} / \mathrm{v}) \mathrm{H}_{2} \mathrm{O}_{2}$ were taken 
in a test tube and kept on ice. The spectrophotometer was adjusted to zero initially and the content of test tube was transferred into a cuvette and the absorbance was taken as initial reading. $0.6 \mathrm{~mL}$ of $4 \%(\mathrm{v} / \mathrm{v})$ guaiacol was added to the cuvette, quickly mixed by inversion and the change in absorbance at $470 \mathrm{~nm}$ was measured for 1,2, 3 and $4 \mathrm{~min}$. In all experiments, three replicates were performed for each sample. The following calculation was used to assay peroxidase activity in a sample: change in $A_{470}=A_{f}-A_{i}$, where, $A_{i}=$ initial absorbance reading and $A_{f}=$ final absorbance reading. Change in $A_{470}$ for each sample was used to calculate the units of POD activity and the activity was expressed as Unit $\mathrm{g}^{-1}$ of root weight.

\subsection{Statistical Analysis}

Results of the experiments were expressed as mean and standard error of different groups based on three independent determinations. The differences between the mean values were evaluated by ANOVA followed by paired t-test using SPSS software.

\section{Results \\ 3.1 Substrate Specificity to PPO Activity in Root after 24h of High Temperature Exposure}

To examine the effects of high temperature on PPO activity in root of Basella alba, different doses of substrates $(10,100$ and $200 \mathrm{mM})$ were employed. As illustrated in Fig. 1, the average PPO activity in root in response to high temperature for $24 \mathrm{~h}$ period was $10243.05 \pm 409.36$ Unit $^{-1}$ of root whereas for control root kept in ambient temperature, the PPO activity was $5186.44 \pm 704.56$ Unit. A significant $97.49 \%(\mathrm{p}<0.01)$ increased PPO activity was observed when the root extracts were treated with $10 \mathrm{mM}$ catechol when compared to the control plant. The results appeared to indicate that an adaptive response by the species of plant was created and the higher synthesis of PPO was observed to serve as the factor in adverse environmental situation. As shown in Fig. 1, the PPO activity in response to $100 \mathrm{mM}$ catechol in root of Basella alba was recorded to determine the effect of high temperature on the regulation of this enzyme activity. The root enzyme level was calculated as $35491.52 \pm 2831.06$ Unit for control and for high temperature induced plant, the value was $55763.88 \pm 1297.32$ Unit $\mathrm{g}^{-1}$ of root. High temperature causes similarly a significant $(\mathrm{p}<0.05)$ increase (57.11\%) in PPO level when compared to the respective control, however, the response was found to be lower than $10 \mathrm{mM}$ substrate concentration for the respective period of exposure. The increase in PPO activity determines the higher anti oxidative status for the prevention of high temperature induced physiological stress of the plant. It is important to note that higher the oxidative stress, higher the synthesis of the enzyme there by the plants survive in the adverse environment. Plants exposed to high temperature for the higher dose of substrate $(200 \mathrm{mM})$ had PPO level $74652.77 \pm 1550.10$ Unit where as for control, the PPO activity $52576.27 \pm 1998.85$ Unit $\mathrm{g}^{-1}$ of root was observed (Fig. 1). The results indicated that the enzyme activity of Basella root had been increased by $41.98 \%(\mathrm{p}<0.05)$ for high temperature treatment when compared to the respective control. The different substrate concentrations were found to be involved in enhancing enzyme activity dose dependently both for the control and high temperature induced plant showing the higher specificity of the substrate for the enzyme.

\subsection{Substrate Specificity to PPO Activity in Root after 48h of High Temperature Exposure}

After $48 \mathrm{~h}$ of treatment, the average PPO activity in root treated with $10 \mathrm{mM}$ substrate was recorded as $10241.37 \pm 977.75$ Unit for high temperature induced plant while for the respective control plant, the value was $7876.71 \pm 479.45$ Unit $\mathrm{g}^{-1}$ of root. High temperature stress has been found to cause $30.02 \%(\mathrm{p}<0.05)$ increased PPO compared to the control plant as illustrated in Fig. 2. The increased synthesis of PPO in root in response to high temperature might be involved in the regulation of metabolic functions of this species of plant. The alteration of PPO level in root is an index for characterization of the sensitivity to the environmental temperature. Similar increased effects on PPO activity $(26.97 \%)(p<0.01)$ in presence of $100 \mathrm{mM}$ catechol were observed significantly when compared to the control where the enzyme activity in root was $58137.93 \pm$ 179.17 Unit for high temperature treatment and for the respective control plant, the activity was recorded as $45787.67 \pm 534.94$ Unit $^{-1}$ of root (Fig. 2). Compared to $10 \mathrm{mM}$ substrate concentration for the similar time, the PPO activity was demonstrated to be lower (Fig. 2). Although increased efficiency of high temperature on PPO activity was demonstrated, however the effects were seemed to be lower than the short term exposure (24h) showing that the temperature sensitivity may induce the activation of this enzyme early and the activity changes with variation of exposure of time. The increased activity in response to high temperature determines the higher conversion of phenolic compounds to the desirable products as this enzyme has higher specificity for the oxidation of phenolic compounds. Figure 2 shows that the PPO level was increased significantly $(p<0.01)$ by $15.76 \%$ in response to higher dose of catechol $(200 \mathrm{mM})$ when they were exposed to $45{ }^{\circ} \mathrm{C}$ compared to the respective control where the values were $59931.50 \pm 576.11$ Unit and $69379.31 \pm 1383.18$ Unit g $^{-1}$ of root respectively for control and high temperature acclimation. 


\subsection{Substrate Specificity to PPO Activity in Root after 72h of High Temperature Exposure}

To find the optimum effect of high temperature exposure on PPO level in root, the extended time was $72 \mathrm{~h}$ and the catechol concentration was $10 \mathrm{mM}$. As shown in Fig. 3, the high temperature induced root had PPO level $8918.03 \pm 429.99$ Unit while for the respective control root, the average PPO level was $6241.61 \pm 323.61$ Unit $\mathrm{g}^{-1}$ of root. The results showed that the PPO level in root had been enhanced significantly $(\mathrm{p}<0.01)$ by $42.88 \%$ when the plants were exposed to high temperature for $72 \mathrm{~h}$ when compared to control. The results appeared to indicate that the PPO levels were severely affected by high temperature acclimation for prolonged exposure however the effects were lower than $24 \mathrm{~h}$ of exposure (Fig. 1 and 3), therefore reasonably assumed to be maximally enhanced after $24 \mathrm{~h}$ of high temperature exposure (Fig. 4). Of course, further extension of time may clarify the mechanism of enhancing the synthesis of PPO in response to high temperature. Whenever the plants were exposed to $45{ }^{\circ} \mathrm{C}$, the PPO activity in root for $100 \mathrm{mM}$ substrate concentration was $43147.54 \pm$ 539.74 Unit while the respective control root had $31845.63 \pm 726.72$ Unit enzyme activity for the above mentioned time. The results (shown in Fig. 3) demonstrated that prolonged exposure of high temperature had been involved in synthesis of enzyme in root of this species of plant and the activity was increased by $35.48 \%$ significantly $(\mathrm{p}<0.001)$ when compared to the respective control, however the efficiency of high temperature on synthesis of enzyme was found to be higher than that of 48h period (Fig. 2 and 3). It is noteworthy that $100 \mathrm{mM}$ catechol causes the higher activity of PPO in root compared to $10 \mathrm{mM}$ concentration for both control and high temperature induced plant. In presence of $200 \mathrm{mM}$ of catechol, high temperature causes the synthesis of PPO enzyme and the activity was $54459.01 \pm 1312.70$ Unit while for the control root, the value was recorded to be $42718.12 \pm 806.06$ Unit $\mathrm{g}^{-1}$ of root showing the higher synthesis of enzyme after $72 \mathrm{~h}$ period and enhanced significantly $(p<0.01)$ by $27.48 \%$ when compared to the respective control however the activity was not declined after $72 \mathrm{~h}$ of exposure rather increased similarly to $24 \mathrm{~h}$ or $48 \mathrm{~h}$ of exposure of high temperature. Although the higher PPO level in root in response to higher dose of substrate was demonstrated for both control and high temperature induced root during the experiment (Fig. 3), the efficiency of high temperature on enhancing increased activity of PPO was assumed to be optimal and higher at $10 \mathrm{mM}$ substrate concentration for 24h of exposure. (Fig. 4). Therefore, the faster increase in enzyme activity in root in response to high temperature acclimation might be dependent on the substrate concentration as well as the period of exposure and might be involved in regulation of metabolism of phenolic substrates by which the plants survive in such a critical environment.

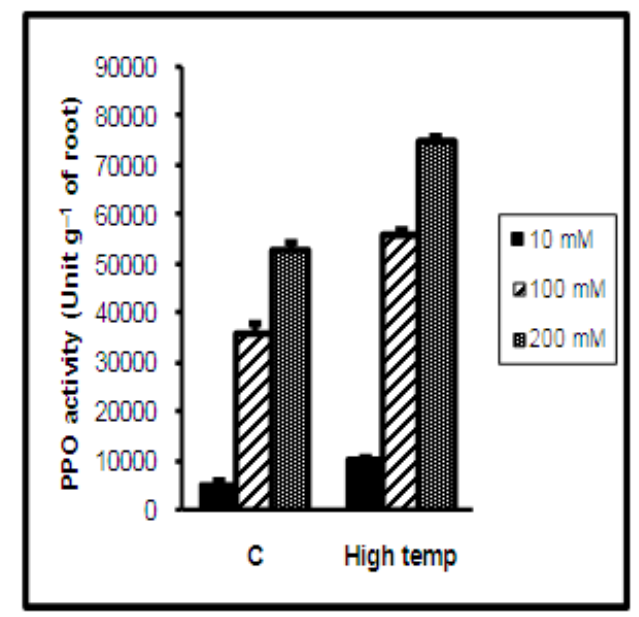

Fig 1. Alteration of PPO activity in response to $10 \mathrm{mM}, 100 \mathrm{mM}$ and $200 \mathrm{mM}$ catechol in roots of Basella alba during high temperature acclimation. The plants were exposed to $45{ }^{\circ} \mathrm{C}$ for $24 \mathrm{~h}$ however the respective controls were used without high temperature exposure. After the treatments, the roots of treated and their respective control plants were used for the assay of PPO activity. 


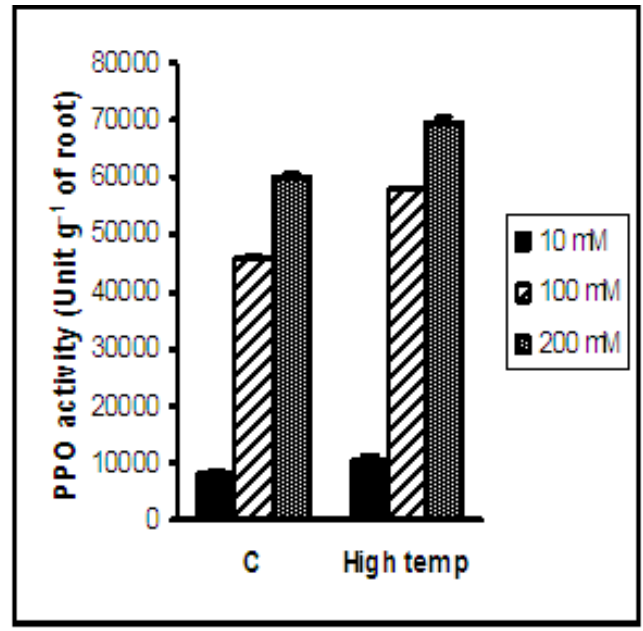

Fig 2. Alteration of PPO activity in response to $10 \mathrm{mM}, 100 \mathrm{mM}$ and $200 \mathrm{mM}$ catechol in roots of Basella alba during high temperature acclimation. The plants were exposed to $45^{\circ} \mathrm{C}$ for $48 \mathrm{~h}$ however the respective controls were used without high temperature exposure. After the treatments, the roots of treated and their respective control plants were used for the assay of PPO activity.

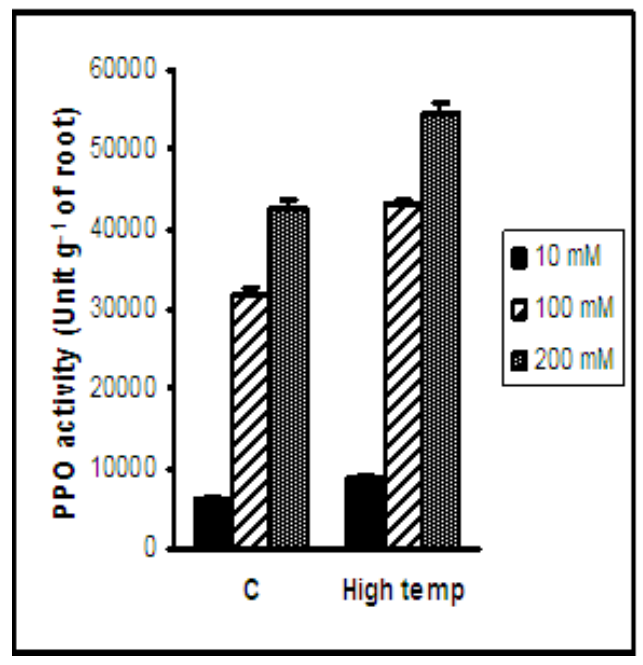

Fig 3. Alteration of PPO activity in response to $10 \mathrm{mM}, 100 \mathrm{mM}$ and $200 \mathrm{mM}$ catechol in roots of Basella alba during high temperature acclimation. The plants were exposed to $45^{\circ} \mathrm{C}$ for $72 \mathrm{~h}$ however the respective controls were used without high temperature exposure. After the treatments, the roots of treated and their respective control plants were used for the assay of PPO activity.

\subsection{Time Course Effect of High Temperature on POD Activity in Root of Basella alba}

Anti oxidative enzymes involved in scavenging system of reactive oxygen species (ROS) include peroxidase. They are a family of isoenzymes found in almost all plants; they are heme-containing monomeric glycoproteins that utilize either $\mathrm{H}_{2} \mathrm{O}_{2}$ or $\mathrm{O}_{2}$ to oxidize a wide variety of molecules. Peroxidase is an oxidoreductase that is directly involved in many plant functions such as hormone regulation, defense mechanisms, indolacetic degradation and lignin biosynthesis. Therefore, during high temperature acclimation, peroxidase might be involved in enzymatic defense of plant cells. To examine the role of high temperature on the regulation of POD activity in root of Basella alba, plants in the pot were exposed to $45{ }^{\circ} \mathrm{C}$ in temperature controlled chamber for $24 \mathrm{~h}$ period and the respective control was kept in ambient room temperature $\left(30^{\circ} \mathrm{C}\right)$. The average POD activity in response to high temperature was $21667.30 \pm 637.59 \mathrm{Unit}^{-1}$ of root whereas for control roots, the POD activity was $33314.23 \pm 1210.42$ Unit. The results demonstrated that POD activity in root had been reduced $(34.96 \%)$ significantly $(\mathrm{p}<0.01)$ by high temperature compared to the respective control (shown in Table 1 and Fig. 5). The decrease in activity in response to high temperature might be the regulatory mechanism of enhancing the synthesis of compounds responsible for browning color since the enzyme has 
higher specificity for the phenolic substrate guaiacol. The higher the activity of this enzyme, higher the conversion of the phenolic substrate to colored o-quinones.

As shown in Table 1, the POD activity in roots of plant was recorded to determine the effect of high temperature on POD synthesis for prolonged exposure. After $48 \mathrm{~h}$ of treatment, the root POD level was estimated as $37000.34 \pm 1082.83$ Unit for control and for high temperature induced plant, the value was $22114.10 \pm 1479.96$ Unit $^{-1}$ of root. High temperature causes a significant and more pronounced decrease in POD activity in root by $40.23 \%(p<0.01)$ (Fig. 5) when compared to the respective control and the decrease of POD activity in root was found to be higher than the previous $24 \mathrm{~h}$ of exposure. Therefore, the activity of this enzyme in root is assumed to be regulated by the variation of temperature and will be strictly followed by the extension of time.

Table 1 also shows the effect of high temperature on POD activity in root of plant after $72 \mathrm{~h}$ of exposure. Plants acclimated to high temperature had root POD level $23866.23 \pm 1372.44$ Unit, whereas $36136.06 \pm 470.18$ Unit $^{-1}$ of root for control plant was observed during the experiment. As the time extended, the average POD activity in root had been enhanced in response to $45^{\circ} \mathrm{C}$ and was increased both for control and high temperature induced plant. High temperature for prolonged exposure causes decreased synthesis of POD significantly $(\mathrm{p}<0.05)$ by $33.95 \%$ compared to the control (Fig. 5), however, the effect was lower than the previous $48 \mathrm{~h}$ of exposure. Although the optimum reduced activity of POD in root was observed after $48 \mathrm{~h}$ of exposure in response to high temperature (Fig. 5), the gradual increase in activity for both the control and high temperature acclimated plant was noted as the time extended. Therefore, the synthesis of POD in root was found to be augmented time dependently however, high temperature causes the deactivation of this enzyme in this species. The results suggest that the reduced POD activity in root might be due to the higher sensitivity of temperature and caused by temperature stress in the environment where they survive and could be considered as the survival factor as well as index for characterization of physiology of root of this species of plant.

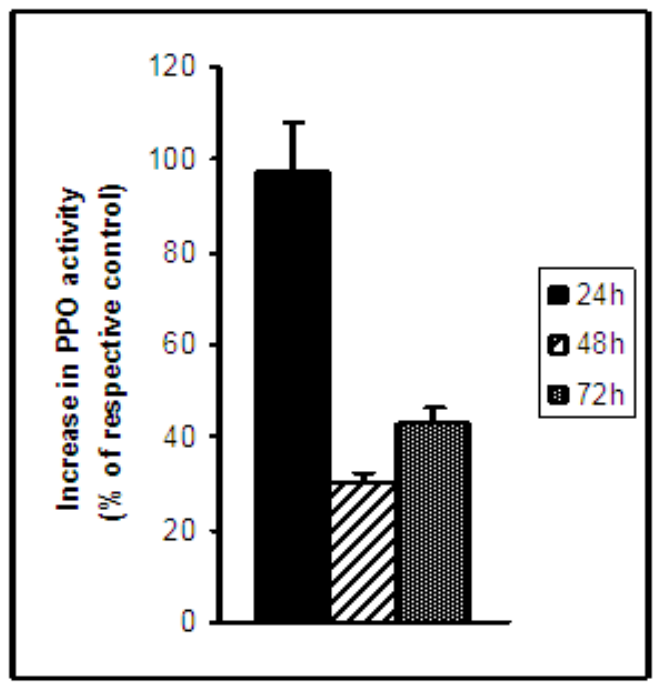

Fig 4. The PPO activity in roots of Basella alba during high temperature acclimation. The plants were exposed to $45{ }^{\circ} \mathrm{C}$ for $24 \mathrm{~h}, 48 \mathrm{~h}$ and $72 \mathrm{~h}$, however, the respective controls were used without any high temperature exposure. After the treatments, the roots of plants and their respective controls were used for the assay of PPO activity using $10 \mathrm{mM}$ substrate concentration. The results are expressed as percentage of the respective controls. 


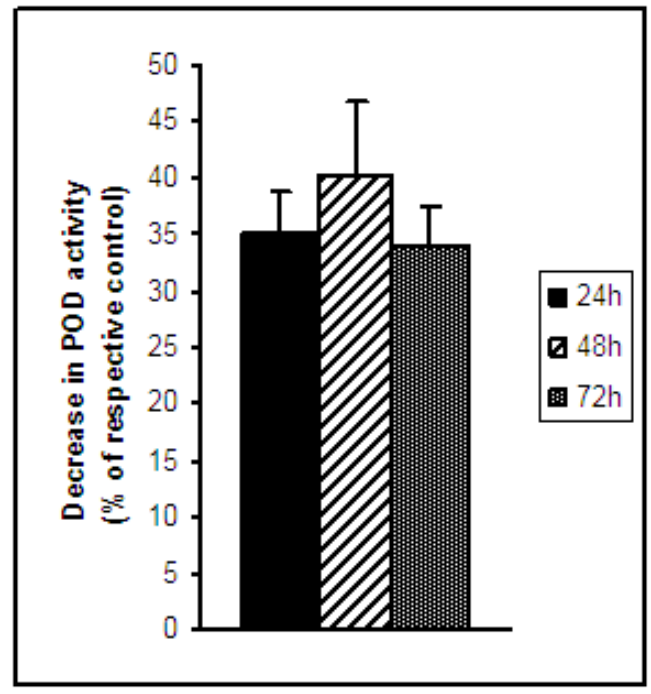

Fig 5. The POD activity in roots of Basella alba during high temperature acclimation. The plants were exposed to $45{ }^{\circ} \mathrm{C}$ for $24 \mathrm{~h}, 48 \mathrm{~h}$ and $72 \mathrm{~h}$, however, the respective controls were used without any high temperature exposure. After the treatments, the roots of plants and their respective controls were used for determination of POD activity. The results are expressed as percentage of the respective controls.

\section{Discussion}

The regulation of polyphenol oxidase and peroxidase activity in root of the species Basella plant was clarified in response to high temperature stress. The enzymes were severely affected and differentially regulated by high temperature stress in this species. We found the strong presence and activity of PPO in roots of the species and the activity was significantly enhanced in response to high temperature treatment. It has been shown that high temperature causes the higher oxidative stress inducing the synthesis of reactive oxygen species (ROS) (17) and increases tolerance to ROS in plants and with an increase in anti oxidative enzymes (18). Anti oxidative enzymes can neutralize ROS and thereby prevents the cellular membranes and organelles from the damaging effects of ROS. It is reasonable that fluctuation of temperature can cause stress to the normal physiological functions of plants, and hence alteration of metabolic activities in root of the plant might be observed. One of the major environmental factors affecting plant growth and productivity is high temperature. Field grown plants are often subjected to fluctuating temperature that has a profound effect on the plant metabolism. Plant responses to environmental stress have been associated with activated forms of oxygen, including hydrogen peroxide $\left(\mathrm{H}_{2} \mathrm{O}_{2}\right)$, singlet oxygen, superoxide, and the hydroxyl radical (19). Heat stress induces or enhances the active oxygen species-scavenging enzymes like superoxide dismutase, catalase and several antioxidants (20). The above findings may argue that the increased activity of PPO in root was because of the increased ROS caused by heat stress.

Plant growth and response to a stress condition is largely under the control of hormones. Hormones, in particular ABA along with cytokinins and ethylene, have been implicated in the root-shoot signaling. This long distance signaling may be mediated particularly via ABA as well as ROS. Recent studies have implicated that the transport of ABA into root xylem is modulated by environmental factors such as xylem $\mathrm{pH}$ and the duration of the day (21). Under the water deficit condition the $\mathrm{pH}$ of xylem sap increases therefore promoting the loading of ABA into the root xylem and its transport to the shoot. Environmental conditions that increase the rate of transpiration also result in an increase in the $\mathrm{pH}$ of leaf sap, which can promote ABA accumulation and lead to reduction in stomatal conductance (21). Increased cytokinin concentration in the xylem sap was shown to promote stomatal opening directly as well as decrease the sensitivity of stomata towards ABA (21).

To find the optimum effect of catechol, dose response characteristics of substrate for the enzyme PPO have been adopted in this study. Among the different concentration of catechol, $10 \mathrm{mM}$ concentration has been found to cause the higher enzyme activity in high temperature induced root although the three different concentrations of catechol $(10 \mathrm{mM}, 100 \mathrm{mM}$ and $200 \mathrm{mM})$ produced the gradual increase in PPO activity for both the control and high temperature induced plants showing the validity of the substrate effect. Accordingly, the higher dose of catechol $(200 \mathrm{mM})$ enhanced the PPO activity maximally in root extract therefore, higher colored quinones were synthesized which might be an effective approach for producing the essential pigments. It has been observed recently that the activity of the crude enzyme from the fruits used was found to decrease at various degrees after incubation for 10 to $120 \mathrm{~min}$ at temperature greater than $70{ }^{\circ} \mathrm{C}(22)$. Therefore, increasing 
the incubation temperature above $70{ }^{\circ} \mathrm{C}$ would cause decrease in the activity of the enzyme and can be a good method of controlling undesirable changes caused by the enzyme in the products of fruits. Polyphenol oxidase activity differs species to species and the activity retains up to $70{ }^{\circ} \mathrm{C}$. The enhanced PPO activity in root of Basella alba caused by high temperature stress therefore, could be compatible and supported by the above findings. Polyphenol oxidase catalyzes the oxidation of phenol to quinone which can covalently modify and crosslink various cellular nucleophiles, undergo melanin-forming auto oxidation reactions, or participate in other reactions. The enzymes are found in higher plants and responsible for the enzymatic browning of raw fruits and vegetables. Such reactions are generally considered to be undesirable in food preservation and processing because of the unpleasant appearance and the concomitant development of a substandard flavor. Moreover, tolerance to high temperature stress in crop plants has been reported to be associated with an increase in antioxidant enzymes activity $(23,24)$.

The function of the phenol oxidase in the roots of $B$ alba remains to be explained. Among the obvious hypotheses are detoxifications, signal transduction or defense against predation (25). An enzyme that functions to defend the plant against toxic compounds in soil would be expected to have broad substrate specificity. PPO activity has been correlated to plant stress, often due to pathogens and herbivores which suggests that this enzyme plays a role in general biotic interaction that might go beyond that of predator avoidance and could involve competitive interactions with other plants (26). The enzymatic destruction of phenolics by roots could alleviate allelopathic inhibition and thus contribute to invasiveness.

Various physiological damages occur in plants upon exposures to varying levels of heat stress. Hydroxyl radicals caused by high temperature can potentially react with all biomolecules, like pigment, proteins, lipids and DNA and almost with all constituents of cells $(27)$. Heat stress $\left(33^{\circ} \mathrm{C}\right)$ induced oxidative stress was observed to damage membrane proteins, protein degradation, enzyme deactivation in wheat that reduced the cell viability remarkably. In the present study, the POD activity in root was found to reduce up to $72 \mathrm{~h}$ periods although the regulatory mechanism and causes are not clarified. However the experimental evidences may support the findings. Diverse environmental stresses differentially affect plant processes that lead to loss of cellular homeostasis accompanied by the formation of reactive oxygen species (ROS), which causes oxidative damage to membrane, lipids, proteins and nucleic acids (2). The coordinate function of antioxidant enzymes such as SOD, APX, catalase and GR helps in processing of ROS and regeneration of redox ascorbate and glutathione metabolites (28). The oxidative damage to cellular components is limited under normal growing conditions due to efficient processing of ROS through a well coordinated and rapidly responsive antioxidant system consisting of several enzymes and redox metabolites. However, under various abiotic stresses the extent of ROS production exceeds the antioxidant defense capability of the cell, resulting in cellular damages. High temperature induced ROS can cause extensive peroxidation and de-esterification of membrane lipids, as well as lead to protein denaturation and mutation of nucleic acids, therefore the reduced POD in response to high temperature in root in the present study might be due to the above reasons. Moreover, peroxidase inactivation was observed in some species of plants and was faster at the higher temperature (29). Tolerant plants entail a tendency of protection against the damaging effects of ROS with the synthesis of various enzymatic and nonenzymatic ROS scavenging and detoxification systems (30). Heat stress has been found to be adversely affected grain yield in wheat (5). Chakrabarty and Pradhan (31) observed that catalase (CAT), ascorbate peroxidase (APX) and superoxide dismutase (SOD) showed an initial increase before declining at 50 ${ }^{\circ} \mathrm{C}$, while peroxidase (POD) and glutathione reductase activities declined at all temperature ranging from 20 to $50{ }^{\circ} \mathrm{C}$. Collectively, the high tempe4ratire has been found to be involved in the regulation of these enzymes in root of this species where PPO and POD were diversely found to be regulated. These two enzymes may play the role in the regulation of the phenolic oxidation in roots and thereby the plants survive in the circumstances.

Table 1: Changes of POD activity in root of Pui vegetable exposed to high temperature. The plants were exposed to $45^{\circ} \mathrm{C}$ for $24 \mathrm{~h}, 48 \mathrm{~h}$ and $72 \mathrm{~h}$ in the high temperature producing chamber. After the treatment, the plants were immediately removed and sampling of root was performed. Control plants were similarly used except giving high temperature exposure.

\begin{tabular}{ll}
\hline Treatments & $\begin{array}{l}\text { Peroxidase (POD) activity } \\
\text { (Unit g } \text { of root) }^{-1}\end{array}$ \\
\hline Control & $33314.23 \pm 1210.42$ \\
$24 \mathrm{~h}$ & $21667.30 \pm 637.59^{\mathrm{A}}$ \\
Control & $37000.34 \pm 1082.83$ \\
$48 \mathrm{~h}$ & $22114.10 \pm 1479.96^{\mathrm{A}}$ \\
Control & $36136.06 \pm 470.18$ \\
$72 \mathrm{~h}$ & $23866.23 \pm 1372.44^{\mathrm{B}}$ \\
\hline
\end{tabular}

The results are means of $\pm \mathrm{SE}$ for three values in each group. ${ }^{A} \mathrm{p}<0.01$ versus respective control. ${ }^{\mathrm{B}} \mathrm{p}<0.05$ versus respective control. 


\section{Conclusions}

It is obvious from the current investigation that high temperature induces diverse metabolic alterations regarding the enhancement of polyphenol oxidase and prevention of peroxidase activity in root therefore, assumes to be involved in the alteration of physiology of plants Basella alba. The adverse environment caused by high temperature produced the severe effect on the plants and thereby plants face the stress to physiological and molecular level and therefore, different regulatory metabolic alterations were observed in the circumstances. High temperature induced oxidative stress and injury is frequently observed in the critical environment and to overcome these effects, some enzymes are over expressed where PPO might be involved. Moreover, denaturation of enzymes and proteins in response to high temperature is commonly observed, thereby peroxidase enzyme has been assumed to be deactivated in this species. Therefore, the anti oxidative enzymes are reversibly regulated by high temperature which is an essential parameter for characterization for the prevention of the anti oxidative effects in this species of vegetables. Species adapted by natural selection to hot environments have evolved a number of physiological and morphological means to improve survival in the face of extended hot periods.

\section{Acknowledgements}

This study was carried out in the Department of Biochemistry and Molecular Biology, Rajshahi University and was supported by the University Grant Commission (UGC), Bangladesh.

\section{References}

[1]. Munns, R. and M. Tester, Mechanisms of salinity tolerance. Ann. Rev. Plant Biol., 2008, 59: 651-681.

[2]. Srivalli, B., C. Vishanathan, and K.C. Renu, Antioxidant defense in response to abiotic stresses in plants. J. Plant Biol., 2003, 30: 121-139.

[3]. Oidaira, H., S. Satoshi, K. Tomokazu, and U. Takashi, Enhancement of antioxidant enzyme activities in chilled rice seedlings. Plant Physiol., 2000, 156: 811-813.

[4]. Lee, D.H. and C.B. Lee, Chilling stress-induced changes of antioxidant enzymes in the leaves of cucumber: In gel enzyme activity assays. Plant Science, 2000, 159(1): 75-85.

[5]. Stone, P.J. and M.E. Nicolas, Wheat cultivars vary widely their responses of grain yield and quality to short periods of post anthesis heat stress. Aust. J. Plant Physiol., 1994, 21: 887-900.

[6]. Mayer, A.M. Polyphenol oxidases in plants and fungi: Going places? A review. Phytochemistry. 2006, 67: 2318-2331.

[7]. Ho, K.K. Characterization of polyphenol oxidase from aerial roots of an orchid. Aranda 'Christine 130'. Plant Physiol. Biochem., 1999, 37: 841-848

[8]. Partington, J.C., C. Smith, and G.P. Bolwell, Changes in location of plyphenol oxidase in potato (Solanum tuberosum L.) tuber during cell death in response to impact injury: comparison with wound tissue. Planta., 1999, 207: 449-460.

[9]. Velero, E., R. Varon, and F. Garcia-Carmona, Catalytic oxidation of acetaminophen by tyrosinase in the presence of L-proline: a kinetic study. Arch. Biochem. Biophys., 2003, 16: 218-226.

[10]. Queiroz, C., M.L.M. Lopes, E. Fialho, and V.L. Valente-Mesquita, Polyphenol oxidase: Characteristics and mechanisms of browning control. Food Rev. Int., 2008, 24(4): 361-375.

[11]. Hiraga, S., K. Sasaki, H. Ito, Y. Ohashi, and H. Matsui, A large family of class III plant peroxidases. Plant Cell Physiol., 2001, 42: $462-468$.

[12]. Chen, E.L., Y.A. Chen, L.M. Chen, and Z.H. Liu, Effect of copper on peroxidase activity and lignin content in Raphanus sativus. Plant Physiol. Biochem., 2002, 40(5): 439-444.

[13]. Premalatha, B. and G. Rajgopal, Cancer- an ayurvedic perspective. Pharmacol. Res., 2005, 51: 19-30.

[14]. Roshan, A., K.H.N. Naveen, and S.D. Shruthi, A review on medicinal importance of Basella alba L. Int. J. Pharma. Sci. Drug Res., 2012, 4(2): 110-114.

[15]. Mahadevan, A. and R. Sridhar, Methods in Physiological Plant Pathology. 2nd ed. Sivakami Publications, Madras, India, pp. 316, 1982.

[16]. Daz, J., A. Bernal, F. Pomar, and F. Merino, Induction of shikimate dehydrogenase and peroxidase in pepper (Capsicum annuum L.) seedlings in response to copper stress and its relation to lignification. Plant Science, 2001, 161(1): 179-188.

[17]. Mahajan, S. and N. Tuteja, Cold, salinity and drought stresses: An overview. Arch. Biochem. Biophys., 2005, 444: 139-158.

[18]. Zhu, J.K. Salt and drought stress signal transduction in plants. Annu. Rev. Plant Physiol. Plant Mol. Biol., 2002, 53: 247-273.

[19]. Anderson, J.A. Catalase activity, hydrogen peroxide content and thermo-tolerance of pepper leaves. Scientia Hort., 2002, 95: 277284.

[20]. Chaitanya, K.V., D. Sundar, S. Masilamani, and A.R. Reddy, Variation in heat stress-induced antioxidant enzyme activities among three mulberry cultivars. Plant Growth Regul., 2002, 36: 175-180.

[21]. Wilkinson, S. and W.J. Davies, ABA-based chemical signaling: the coordination of responses to stress in plants. Plant Cell Environ., 2002, 25: 195-210.

[22]. Bello, A.B. and M.S. Sule, Optimum temperature and thermal stability of crude polyphenol oxidase from some common fruits. Nigerian Journal of Basic and Applied Science, 2012, $20(1): 27-31$.

[23]. Sairam, R.K., G.C. Srivastava, and D.C. Saxena, Increased antioxidant activity under elevated temperature: a mechanism of heat stress tolerance in wheat genotypes. Biol. Plant., 2000, 43: 245-251.

[24]. Zhau, R.G., Z.H. Fan, X.Z. Li, Z.W. Wang, and W. Han, The effect of heat acclimation on membrane thermo-stability and reactive enzyme activity. Acta Agron. Sin., 1995, 21: 568-572.

[25]. Bais, H.P., B. Prithiviraj, A.K. Jha, F.M. Ausubel, and J.M. Vivanco, Mediation of pathogen resistance by exudation of antimicrobials from roots. Nature, 2005, 434: 217-221.

[26]. Hachinohe, M. and H. Matsumoto, Mechanism of selective phytotoxicity of 1-3, 4-dihydroxyphenylalanine (L-DOPA) in barnyardglass [sic] and lettuce. Journal of Chemical Ecology, 2007, 33: 1919-1926.

[27]. Moller, I.M., P.E. Jensen, and A. Hansson, Oxidative modifications to cellular components in plants. Ann. Rev. Plant Biol., 2007, 58: 459-481. 
[28]. Foyer, C.F. and G. Nector, Oxygen processing in photosynthesis regulation and signaling. New Phytol. 2000, 146: 359-388.

[29]. Muftugil, N. The peroxidase enzyme activity of some vegetables and its resistance to heat. J. Sci. Food Agric., 1985, 36: 877-880.

[30]. Apel, K. and H. Hirt, Reactive oxygen species: metabolism, oxidative stress and signal transduction. Ann. Rev. Plant Biol., 2004, 55: 373-399.

[31]. Chakraborty, U. and D. Pradhan, High temperature-induced oxidative stress in Lens culinaris, role of antioxidants and amelioration of stress by chemical pre-treatments. J. Plant Interact., 2011, 6: 43-52. 